\section{Photoperiod Affects Growth and Flowering of Lysimachia clethroides Duby}

\author{
Pamela M. Lewis ${ }^{1}$, Allan M. Armitage ${ }^{2}$, and James M. Garner ${ }^{3}$ \\ Department of Horticulture, University of Georgia, Athens, GA 30602-7273
}

Additional index words. cut flowers, gooseneck loosestrife, limited inductive photoperiod

\begin{abstract}
Gooseneck loosestrife (Lysimachia clethroides Duby) rhizomes were cooled for 10 weeks at $4 \pm 1{ }^{\circ} \mathrm{C}$ prior to greenhouse forcing in continuous long days (LD); continuous short days (SD); 4, 6, 8, or 10 weeks of SD followed by LD until anthesis; and 4, 6, 8, or 10 weeks of $L D$ followed by SD. None of the plants grown in continuous SD flowered, and fewer than $30 \%$ of plants flowered when grown in 4, 6 , or 8 weeks of LD followed by SD for 21 to 25 weeks. At least 10 weeks of LD prior to SD were required to obtain $70 \%$ flowering. Plants receiving continuous LD or 4, 6, or 8 weeks of SD followed by LD flowered in the highest percentages $(85 \%$ to $90 \%$ ), but only $10 \%$ of plants receiving 10 weeks of SD followed by LD flowered. The number of greenhouse days required for visible bud formation and anthesis increased linearly as initial SD exposure increased, but the number of racemes produced by flowering plants was not affected. Plant height was greatest in continuous $\mathrm{LD}$, and decreased linearly as initial SD exposure prior to LD increased from 0 to 10 weeks. Plants grown in continuous SD remained vegetative rosettes throughout the experiment, and their height increased linearly as initial LD prior to SD increased from 0 (continuous SD) to 10 weeks. These results demonstrate that supplemental LD lighting can promote growth and flowering in this species and that lighting can be discontinued 3 weeks before harvest of cut flower crops.
\end{abstract}

The long stems and curving, white racemes of Lysimachia clethroides make it particularly well-suited for specialty cut flower production. Under field conditions, this herbaceous perennial produces flowers during late spring or early summer, but the year-round demand for specialty cut flowers makes off-season greenhouse forcing desirable. Iversen and Weiler (1994) found that $L$. clethroides can be forced to flower in the greenhouse in a 16- or 24-h photoperiod but not in an 8-h photoperiod. This suggests that $L$. clethroides has a qualitative continuous long days (LD) requirement for flowering, but many questions remain about the photoperiodic response of this plant.

Iversen and Weiler (1994) exposed $L$. clethroides to continuous 8-, 16- or 24-h photoperiods. However, many herbaceous perennials do not require continuous exposure to inductive photoperiods to complete flowering. Trachelium caeruleum $\mathrm{L}$. requires $\mathrm{LD}$ for flower initiation but not for subsequent flower development (Armitage, 1988). After initiation in LD, floral organs of $T$. caeruleum will develop and function properly in continuous

Received for publication 26 Oct. 1998. Accepted for publication 16 Aug. 1999. We thank Here \& Now Gardens, Gales Creek, Ore., for donating the rhizomes used in this study. The cost of publishing this paper was defrayed in part by the payment of page charges. Under postal regulations, this paper therefore must be hereby marked advertisement solely to indicate this fact.

${ }^{1}$ Research Specialist. E-mail address: jmgarner@ arches.uga.edu

${ }^{2}$ Professor of Horticulture. E-mail address: armitage@ arches.uga.edu.

${ }^{3}$ Graduate Research Assistant. short days (SD). In contrast, Hamelia patens Jacq. and Asclepias tuberosa L. have critical photoperiods for flower development but are day-neutral for flower initiation (Albrecht and Lehmann, 1991; Armitage, 1995). Occasionally, photoperiodic requirements for initiation differ from those for development. Salvia leucantha L. is a SD plant with critical photoperiods of $12 \mathrm{~h}$ for flower initiation and a critical photoperiod of $10 \mathrm{~h}$ for development to anthesis (Armitage and Laushman, 1989).

Photoperiod also influences the growth habit of many plants. Although photoperiod does not affect flower initiation and development in Zantedeschia elliottiana (W. Wats.) Engl. or Z. rehmannii Engl., LD provided by night-interruption (NI) lighting promotes peduncle elongation (Corr and Widmer, 1990). Similarly, Zinnia elegans Jacq. flowers most rapidly in $\mathrm{SD}$, but produces higher quality cut flowers in LD, since plant height, node number, flower diameter, leaf length, and leaf width are increased (Boyle and Stimart, 1983). Manipulation of photoperiod with alternating cycles of LD and SD may also be useful in production of cut flower crops to enhance flowering stem yield and quality. Liatris spicata (L.) Willd. produced the highest yields of long-stemmed cut flowers when an initial 35d SD treatment was followed by LD (Espinosa and Healy, 1990).

Iversen and Weiler (1994) showed that $L$. clethroides does not flower in SD, and subsequent studies on growth and flowering of this crop in response to cooling were conducted under LD conditions (Lewis et al., 1999). The influence of alternating photoperiods during greenhouse forcing of this crop have not been investigated, and this information may be of value to cut flower producers. The objective of this study was to evaluate the effect of LD, SD, and alternating LD and SD on progress to flowering, percentage of plants flowering, plant height, and size of racemes and flowering stems produced from $L$. clethroides rhizomes forced under greenhouse conditions.

\section{Materials and Methods}

Expt. 1. Continuous and noncontinuous photoperiod. On 10 Oct. 1995, 500 L. clethroides rhizomes were harvested from outdoor production beds (Here \& Now Gardens, Gales Creek, Ore.), packed into plastic bags filled with unmilled sphagnum peatmoss, and shipped to Athens, Ga. Upon arrival, 260 rhizomes $\approx 9 \mathrm{~cm}$ long were selected for uniformity and packed into crates $(36 \times 34 \times 27 \mathrm{~cm})$ lined with clear, 0.2-mmthick (8-mil) polyethylene. Each crate contained five single layers of rhizomes packed between layers of moist, unmilled sphagnum peatmoss. The crates were stored in darkness in a cooler at $4 \pm 1^{\circ} \mathrm{C}$ for 10 weeks. To allow aeration, the tops of the crates were left open during cooling. At the commencement of cooling, the unmilled sphagnum peatmoss contained $\approx 90 \%$ water by weight, and tap water was added as needed during cooling to maintain uniform moisture within the crates.

After cooling, the rhizomes were potted into 3.8-L nursery containers filled with a commercial soilless medium (Fafard Mix No. 3-B; Conrad Fafard, Anderson, S.C.). The pots were then placed on benches in a glasshouse in which the ambient temperature averaged $20 \pm 5^{\circ} \mathrm{C}$ (day) and $19 \pm 3{ }^{\circ} \mathrm{C}$ (night) throughout the experiment. On 2 Feb. 1996, 200 uniform plants with an average height of $3 \mathrm{~cm}$ and an average of six leaves were selected and randomly divided into two groups of 100 . One group received LD photoperiod from NI lighting provided by $40-\mathrm{W}$ incandescent bulbs (Sylvania, St. Marys, Pa.) from 2200 to $0200 \mathrm{HR}$ at an average intensity of 14 $\mu \mathrm{mol} \cdot \mathrm{m}^{-2} \cdot \mathrm{s}^{-1}$ at plant height. The other group received SD photoperiod (11 h) by application of blackcloth from 1700 to 0800 HR. Application of blackcloth during these hours was made to both LD and SD treatments to control daily light integral and to ensure that ambient conditions were similar among treatments.

After 4 weeks of photoperiod treatments, $20 \mathrm{LD}$ plants were moved to SD treatments, and $20 \mathrm{SD}$ plants were moved to LD treatments. This process was repeated after 6,8 , and 10 weeks to give eight different photoperiod combinations in addition to a continuous LD and continuous SD treatment (Fig. 1). At the time of each transfer, all replicates were completely randomized across the greenhouse benches. Treatments were continued until 24 Aug. (29 weeks after photoperiod treatments were begun) when the study was ended.

All plants were given $200 \mathrm{mg} \cdot \mathrm{L}^{-1} \mathrm{~N}$ constant liquid feed, alternating applications of $15 \mathrm{~N}-9.9 \mathrm{P}-14.1 \mathrm{~K}$ and $15 \mathrm{~N}-0 \mathrm{P}-12.5 \mathrm{~K}$ (Peter's 15-16-17 Peat-lite Special and 15-0-15 Dark Weather Feed, respectively; The Scotts Co., 


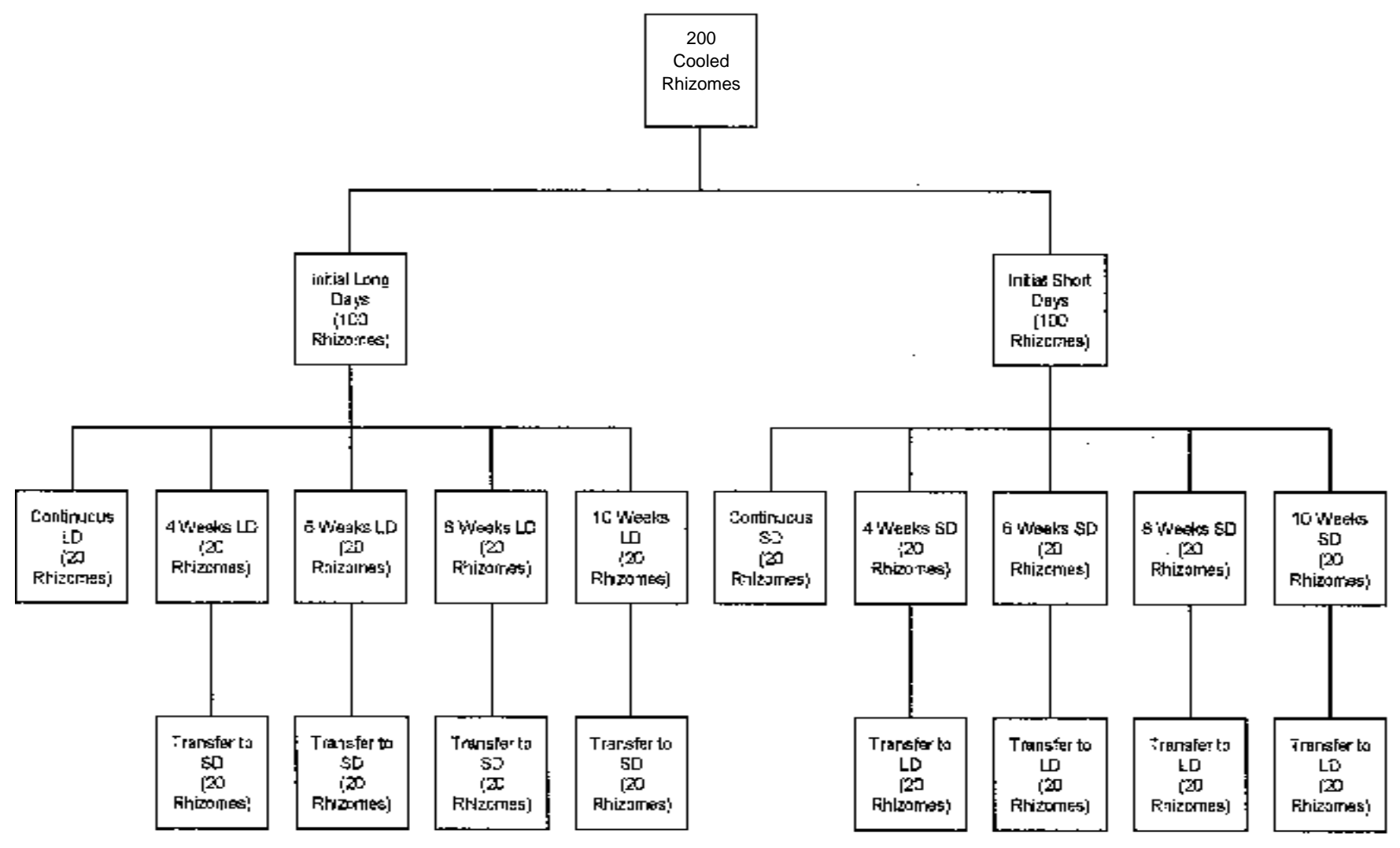

Fig. 1. Design for continuous and noncontinuous photoperiod study.

Marysville, Ohio). Once a week, all pots were leached with tap water to prevent excessive build-up of soluble salts.

The numbers of greenhouse days until visible bud formation and anthesis were recorded for the flowering plants in each treatment. All flowering stems were harvested when about one-third of all flowers in a raceme were open. Terminal racemes on main shoots were cut at a height allowing the maximum number of potential flowering branches to remain intact on the plant while providing a cut flower stem of $\geq 40 \mathrm{~cm}$. Side branches of the main shoots bearing racemes were cut at the junction of the branch and the main shoot. Data were recorded for each flowering stem produced, and included stem length and diameter; raceme number, length, and width; flower diameter; and bract length. Raceme length was measured from the axil of the lowest flower in the raceme to the tip of the uppermost bud, and raceme width was measured at the middle of the raceme. Stem length was measured from the cut end of the stem to the axil of the lowest flower and stem diameter was measured with calipers $\approx 2.5 \mathrm{~cm}$ above the cut end of the flower stem. Overall plant height was also recorded at the time of harvest or, for nonflowering plants, at the completion of the experiment. All data were tested by analysis of variance (ANOVA) using the SAS General Linear Model procedure (SAS Inst., Cary, N.C.), and variation among initial photoperiod treatments was analyzed by orthogonal contrasts.

Table 1. Bud stage of development for Lysimachia clethroides at the initiation of final short day or long day treatments.

\begin{tabular}{lcl}
\hline Group no. & Bud size & \multicolumn{1}{c}{ Description } \\
\hline 1 & $\begin{array}{r}<.5 \mathrm{~cm} \\
2.5-3.0 \mathrm{~cm}\end{array}$ & $\begin{array}{l}\text { Buds very small, nestled in leaves, only thread-like bracts are visible. } \\
\text { Buds protrude from uppermost leaves, a few individual flower buds (round } \\
\text { and green) are discernible on the developing raceme. } \\
\text { More individual flower buds are visible on the developing raceme, the } \\
\text { lower flower buds are green and white. }\end{array}$ \\
$4.0-5.0 \mathrm{~cm}$ & $\begin{array}{l}\text { Individual flower buds are visible near the apex of the developing raceme, } \\
\text { lower flower buds have lost their green coloration and are completely white. }\end{array}$
\end{tabular}

Expt. 2. Flower development. Plants in which flower buds had initiated in LD were transferred to SD at different developmental stages to determine the influence of SD on flower development. Rhizomes of L. clethroides used in this study received natural cooling in the field and were harvested in Mar. 1996 (Here \& Now Gardens). The rhizomes received no additional cooling prior to potting in 3.8-L containers filled with a commercial soilless medium (Fafard 3-B, Conrad Fafard). Plants were initially grown in the previously described greenhouse conditions, and received LD from NI lighting providing $14 \mu \mathrm{mol} \cdot \mathrm{m}^{-2} \cdot \mathrm{s}^{-1}$ at plant level from 2200 to $0200 \mathrm{HR}$. On 15 June 1996, 100 plants with flower buds were selected and grouped according to flower bud stage of development ranging from 2.5 to $7 \mathrm{~cm}$ in length (Table 1). Half of the plants in each group remained in $\mathrm{LD}$, while the other half received SD $(11 \mathrm{~h})$ provided by blackcloth application from 1800 to $0900 \mathrm{HR}$. Application of blackcloth during these hours was made to both LD and SD treatments to control daily light integral and to insure that ambient conditions were similar among treatments. When about one-third of the flowers in a raceme reached anthesis, raceme length and width, numbers of flowers or buds per raceme, bract length, flower diameter, and the number of days required to attain anthesis were recorded for each flowering stem. Data were tested by ANOVA using the SAS General Linear Model (SAS Inst.), and means separation was accomplished using Tukey's Studentized range test (HSD).

\section{Results and Discussion}

Effect of continuous SD or LD. None of the plants grown in continuous SD flowered, while $>80 \%$ of plants grown in continuous LD or 4,6 , or 8 weeks SD prior to $\mathrm{LD}$ flowered (Fig. 2A). These findings are similar to those of Iversen and Weiler (1994), who reported that $L$. clethroides remained 


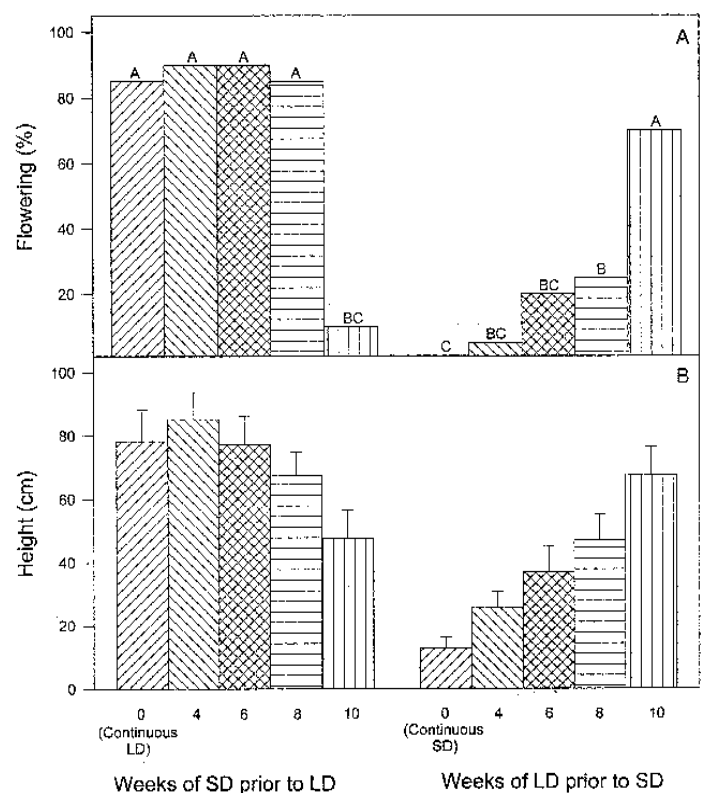

Fig. 2. Effects of continuous or noncontinuous long day (LD) or short day (SD) photoperiod on (A) percentage of plants flowering and (B) overall plant height of Lysimachia clethroides. Each bar in (A) represents the average of four groups of five single-plant replicates. Mean separation by Tukey's Studentized range test (HSD), $P \leq 0.05$. Trends in (B) for SD prior to LD plants and for LD prior to SD plants are linear at $P \leq 0.001$. Error bars represent standard deviation about the means.

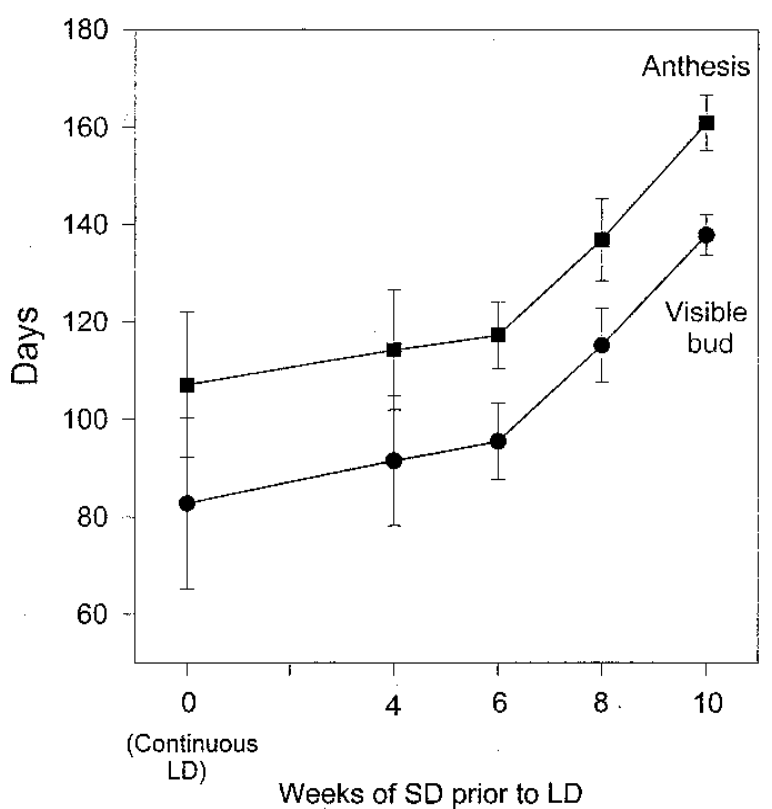

Fig. 3. Total time to visible bud and anthesis for Lysimachia clethroides forced in continuous long days (LD) or 4, 6, 8, or 10 weeks of short days (SD) followed by LD. Bars represent standard deviations about the means. Both trends are linear at $P \leq 0.001$. vegetative when grown in an 8-h photoperiod, regardless of previous exposure to cooling. These data confirm that $L$. clethroides has a qualitative flowering response to LD. The failure of some plants to flower in LD treatments suggests that some rhizomes used in this study may not have reached maturity prior to harvest.

Effect of transfer from SD to $L D$. Plant height decreased linearly as initial SD exposure increased from 0 to 10 weeks (Fig. 2B). In continuous $\mathrm{SD}$, the average vegetative plant height of L. clethroides was $12.8 \mathrm{~cm}$, but further progress to flowering required LD exposure. The earliest flower initiation occurred in continuous LD; the number of greenhouse days required for visible bud formation (VB) and anthesis (FLW) increased linearly as initial SD exposure increased from 0 to 10 weeks (Fig. 3). Twenty to $25 \mathrm{~d}$ were required for VB to FLW, regardless of treatment, suggesting that VB to FLW was not affected by photoperiod.

There was no correlation between the number of SD cycles received and progress to flowering. Plants grown in continuous LD flowered in $\approx 107 \mathrm{~d}$. However, plants exposed to 4 weeks of SD before transfer to LD flowered just $7 \mathrm{~d}$ later, and 6-week SD plants just $10 \mathrm{~d}$ later than did plants grown in continuous LD (Fig. 3). Exposure to SD for 8 or 10 weeks had no more effect on time to FLW than did exposure to 6 weeks (Fig. 4). The reduction in the number of inductive photoperiods required for flowering as initial SD exposure increased may indicate increasing sensitivity to $\mathrm{LD}$ as maturation proceeds, while the reduction in the number of flowering plants after 10 weeks of SD may suggest a decrease in sensitivity to LD. L. clethroides may pass through juvenility gradually, with sensitivity to inductive photoperiods gradually increasing and then declining again as maturation proceeds. Damann and Lyons (1993) noted this pattern of behavior in Coreopsis lanceolata L. 'Early Sunrise', a qualitative LD plant; plants flowered later when moved to inductive LD at the cotyledon stage or at the 24-leaf stage than when transferred at the 16-leaf stage.

The number of racemes produced by flowering plants was similar among treatments, regardless of the percentage of plants that flowered (data not shown). An increase in lateral branching, promoted by noninductive $\mathrm{SD}$, was credited with increasing cut flower yields of the LD plants Helipterum roseum (Hook.) Benth., Helichrysum bracteatum (Venten.) Andr., and Gerbera jamesonii Bolus (Cockshull, 1985; Lin and French, 1985; Sharman et al., 1989). In contrast, initial exposure of $L$. clethroides to SD did not increase lateral branching or cut flower yield. Plants grown under SD for 4, 6, or 8 weeks produced short rosettes, and branching occurred only after transfer to LD. Therefore, initial SD exposure for 4, 6, or 8 weeks prior to LD delayed flowering without significantly enhancing cut flower yield.

Effect of transfer from $L D$ to $S D$. To obtain a significant flowering response, $L$. clethroides required prolonged exposure to LD. When transferred to SD after 4 weeks of $\mathrm{LD}$, only $5 \%$ of the plants flowered. At least 10 weeks of $\mathrm{LD}$ prior to SD were required to obtain $70 \%$ flowering (Fig. 2A). Although
LD are required for flower initiation, they do not appear to be necessary for subsequent flower development. All plants exhibiting visible buds at the time of transfer to noninductive SD flowered, as did all plants in which buds became visible shortly after SD transfer (data not shown). However, no plants developed visible buds under continuous SD, and after several weeks in SD, no additional visible buds appeared on plants transferred from LD. This suggests that the plants that flowered in SD had previously undergone induction and initiation during LD.

Raceme length increased linearly with initial exposure to LD (Fig. 5A). Following transfer to SD, the buds initiated in LD continued to develop, but no new buds were initiated (data not shown). Although flower development continued after transfer to SD, SD conditions appeared to inhibit extension growth. Both plant height and flowering stem length increased linearly with length of initial exposure to LD (Fig. 5B). These data suggest that $L$. clethroides resembles Coreopsis lanceolata 'Early Sunrise', which requires LD for floral initiation and stem elongation but not for normal development of floral organs (Damann and Lyons, 1993).

Effects of photoperiod on flower development. Abnormally short racemes were produced on plants receiving 4 weeks of LD prior to SD (Fig. 5A). Visible buds were not observed on these plants at the time of transfer to $\mathrm{SD}$, and the stunted racemes suggest that either floral initiation ceased prematurely or some developing buds in the raceme aborted following transfer. When plants with visible buds at various stages of development 


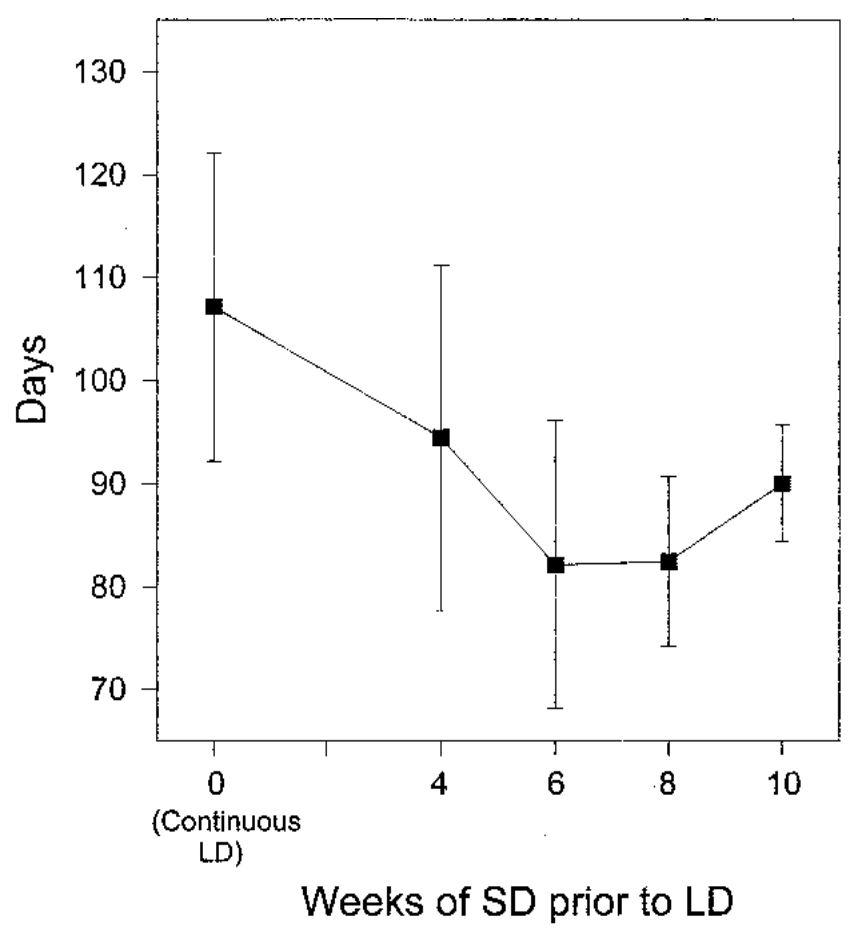

Fig. 4. Time from start of long days (LD) to anthesis for Lysimachia clethroides forced in continuous $\mathrm{LD}$ or $4,6,8$, or 10 weeks of short days (SD) followed by LD. Bars represent standard deviations about the means. Trend is quadratic at $P \leq 0.01$.

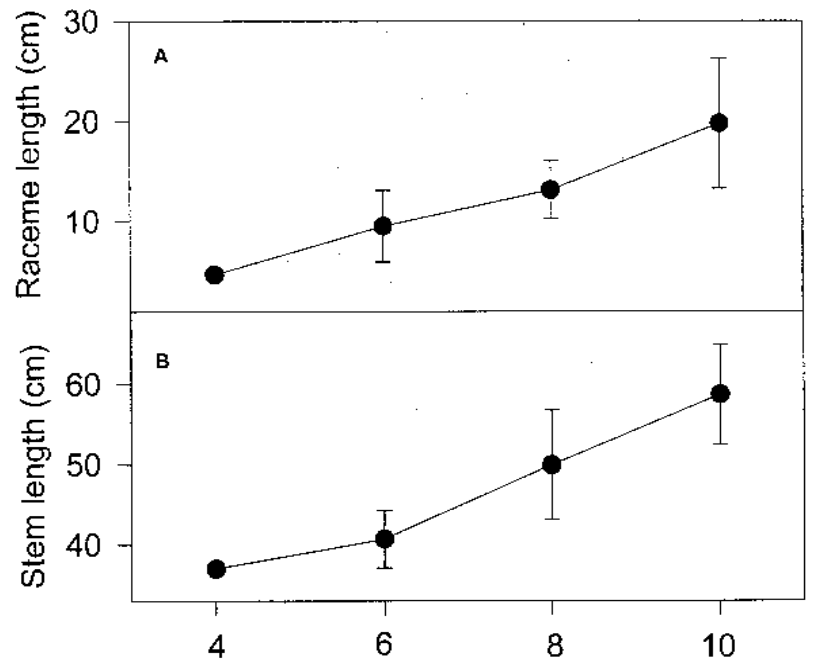

Weeks of LD prior to SD

Fig. 5. Raceme length (A) and flowering stem length (B) for Lysimachia clethroides forced in 4, 6, 8, or 10 weeks of long day (LD) followed by short day (SD) photocopied. Bars represent standard deviations about the means. Both trends are linear at $P \leq 0.01$.

were transferred from LD to SD, flower development proceeded at the same rate and to the same degree as in plants remaining in LD (data not shown). Days to FLW, raceme size, flower number and diameter, and bract length were not significantly affected by transfer to SD. Thus, to obtain the earliest harvest of cut flowers during the short photoperiods of winter, LD must be applied until flower buds become visible on all plants. After attaining the visible bud stage, racemes will develop at the same rate and to the same degree in either SD or LD.

Photoperiod influenced both the vegetative and reproductive development of $L$. clethroides. At least 10 weeks of LD were required to obtain flowering in $70 \%$ of all plants, and plants remained vegetative rosettes when grown in continuous SD. Therefore, during periods of naturally short daylength (winter), NI lighting should be applied for 10 or more weeks after emergence to obtain a high percentage of flowering plants. However, this treatment may be delayed for over a month after shoot emergence, if necessary, without adversely affecting plant height or the rate of flowering. The highest flowering percentages were obtained for continuous LD plants and those receiving fewer than 10 weeks of SD prior to LD, suggesting that the ability of $L$. clethroides to respond to inductive photoperiods may be reduced after exposure to 10 weeks of SD. Unlike many other LD plants, initial exposure to SD did not increase yield or length of flowering stems for $L$. clethroides, and the number of racemes produced by flowering plants was not affected by transfer from SD to LD. The influence of incandescent lighting on plant height (Fig. 2B) and raceme length (Fig. 5A) may not be attributable solely to $\mathrm{LD}$, since light emitted from these lamps has a low R : FR ratio that can in itself promote stem elongation. However, these results do support the use of NI lighting in production of $L$. clethroides cut flowers. Lighting of crops produced during noninductive or marginal photoperiods should begin as soon as possible after emergence to promote induction of flowering, progress to anthesis, and extension of flowering stems. Lighting can be discontinued 3 weeks before production stops.

\section{Literature Cited}

Albrecht, M. and J.T. Lehmann. 1991. Daylength, cold storage and plant production method influence growth and flowering of Asclepias tuberosa. HortScience 26:120-121.

Armitage, A.M. 1988. Effects of photoperiod, light source and growth regulators on the growth and flowering of Trachelium caeruleum. J. Hort. Sci. 63:667-674.

Armitage, A.M. 1995. Photoperiod, irradiance, and temperature influence flowering of Hamelia patens (Texas firebush). HortScience 30:255256.

Armitage, A.M. and J.M. Laushman. 1989. Photoperiodic control of flowering of Salvia leucantha. J. Amer. Soc. Hort. Sci. 114:755758

Boyle, T.H. and D.P. Stimart. 1983. Developmental responses of Zinnia to photoperiod. J. Amer. Soc. Hort. Sci. 108:1053-1059.

Cockshull, K.E. 1985. Gerbera, p. 43-47. In: A.H. Halevy (ed.). Handbook of flowering. vol. 3. CRC Press, Boca Raton, Fla.

Corr, B.E. and R.E. Widmer. 1990. Growth and flowering of Zantedeschia elliottiana and $Z$. rehmannii in response to environmental factors. HortScience 25:925-927.

Damann, M P. and R.E. Lyons. 1993. Juvenility, flowering, and the effects of a limited inductive photoperiod in Coreopsis grandiflora and $C$. lanceolata. J. Amer. Soc. Hort. Sci. 118:513518.

Espinosa, I. and W. Healy. 1990. Influence of photoperiod on Liatris spicata generative shoot growth. HortScience 25:764-766.

Iversen, R.R. and T.C. Weiler. 1994. Strategies to force flowering of six herbaceous garden perennials. HortTechnology 4:61-65.

Lewis, P.M., A.M. Armitage, and J.M. Garner. 1999. Cooling accelerates flowering of Lysimachia clethroides Duby. HortScience 34:239-241.

Lin, W.C. and C.J. French. 1985. Effect of supplementary lighting and soil warming on flowering of three Gerbera cultivars. HortScience 20:271-273.

Sharman, K.V., M. Sedgley, and D. Aspinall. 1989. Effects of photoperiod, temperature and plant age on floral initiation and inflorescence quality in the Australian native daisies Helipterum roseum and Helichrysum bracteatum in relation to cut-flower production. J. Hort. Sci. 64:351-359. 